\title{
A Need Analysis of English for Specific Purposes (ESP) Course for Adoption of Communicative Language Teaching (A Case of First Year Engineering Students of Quest Nawabshah)
}

\author{
Ruqia Bano Mastoi \\ MS Scholar at ELDC Mehran University of Engineering and technology,Jamshoro \\ Syed Waqar Ali Shah \\ Lecturer at ELDC Mehran University of Engineering and technology,Jamshoro \\ Shoukat Ali Lohar \\ Assistant Professor at ELDC Mehran University of Engineering and technology,Jamshoro
}

\begin{abstract}
English has become one of the global languages. It has great importance everywhere in education, business and in everyday interactions. Because of the global status of English its teaching should be accordingly to its use in daily life. Many methodologies of teaching English have been implemented but one of the modern methodoly is communicative language teaching (CLT). It is one of the strategies that are very much beneficial for teaching English communicatively. CLT is implemented in EFL/ESL and also in ESP courses. In Pakistan, still GTM (grammar translation method) is implemented, CLT is not been used because traditional methodologies are easy to apply in the classroom. The aim of this research is to find out basic needs and lacking's in our universities of Pakistan in teaching ESP in engineering context. This paper is also aimed to assess the needs of CLT in the engineering context. In order to get the result, mixed questionnaire of multiple option questions are used as an instrument of the data collection. 12 questions are asked to know the student's perception of CLT teaching. Only students have been taken as the participant of the study. 130 students from the Quest University Nawabshah have been selected from the different departments to achieve goal of assessing students' belief's and attitudes towards CLT.

DOI: $10.7176 /$ JLLL/55-01

Publication date: April $30^{\text {th }} 2019$

\section{Introduction}

The English language is one of the international languages. It is second language of Asian countries. In Pakistan English language is official and academic one. But when we are talking of its teaching, it is not taught in communicative way. Teaching of English is still going through old methodologies in Pakistani universities. This study aimed at presenting CLT as a method of teaching English communicatively in Universities of Pakistan. The language must be taught according to its context, use and needs. The modern technologies and methodologies should be implemented to get relevant goals of the language use. The ESP should be taken into consideration while teaching English. In Pakistan English is considered as a second language. A person with better English can have a bright future in his/her professional life. In every field like business, education and everyday communication English is of prime importance. If one wanted to excel s/he should learn English communicatively.
\end{abstract}

\section{English as a global language}

The most important attribute of human nature is communication. Without this human life is impossible to survive. In the past decades, the communication was not global. It was within the societies, culture and communities. After expansion of business and trade it became necessary to communicate globally to achieve the goals. Language varies culture to culture and community to community. People of this era wanted to communicate globally to fulfill their academic and professional goals. After renaissance, because of expansion in business and English colonialism, English has achieved the prestigious status and became the international language. Now it is considered as language of world. Everywhere you find English as second language of the majority of countries. It also became the one of the common language of different people of different countries and cultures.

English is getting higher status day by day, because of its needs has been growing in terms of education, business and trade.

\section{English language teaching in engineering context of Pakistani universities}

Pakistan is one of the multilingual countries. In Pakistan English is one of the important subjects. It is taught 
from grade one to graduation as a one of the basic subject. English is considered as one of the important language in Pakistani education.

But when we are talking about the English language communication it is not very satisfactory. Language teaching in Pakistan is not taught in terms of its usage. Its teaching is still of traditional way. GTM is still implemented in teaching English language in the ESP courses.

There is lack of deep learning and contextual learning in language teaching only rote learning is suggested by the teachers. Grammar is only focused. Only focus is on transmission of knowledge, lecture method, and passive learning. In this modern era still teacher is considered as authority of the classroom and students are considered as silent listeners. As English is one of the primary secondary languages of Pakistan so it is most important to learn English for getting job. English is most important to learn communicatively else it is of no use to learn grammar and vocabulary. GTM is still being implemented by the teachers and course designers and it is not benefitted for the learners. There are still barriers in CLT in Pakistani context. For engineers English is also necessary, for international organizations, publications and other related field work. Engineers whose English language is not good they find so many difficulties in their professions. They cannot communicate internationally and they can't excel in their fields. CLT is facing many problems in Pakistani context while in many non-native countries of English are adopting CLT for English language. In order to meet the international status of engineering, engineers must know English communicatively.

\section{Need Analysis}

A need analysis is the way of recognizing and assessing the needs of the language learner and learning objects. Through need analysis, teacher can have idea about the students' needs and objectives of learning English. It is very necessary for a teacher to know about the student's learning background, his/her skills that $\mathrm{s} /$ he has and wanted to improve and design the course that will benefit him/her related to his/her field of interest. It also fulfills the gaps of what student knows and what s/he wanted to know. It also focuses on the contextual learning.

\section{Research Aim}

The research aimed to analyses the needs of ESP course in engineering context. It also focuses on adoption of CLT as the one of the useful methodology in teaching English language communicatively. ESP course should be designed according to its learner's needs.

\section{Literature Review}

English language is one of the languages that are in majority spoken by non-native speakers. The idea of having prestigious status being native speaker has been now weakened. The non-native speakers of English are increasing. Everywhere CLT is adopted for language teaching, because it promotes English fluency and accuracy and focuses on communication rather grammar. But CLT is still facing many obstacles in many countries as Pakistan, Korea, China, Japan, and other.

Ramanathan wrote that most popular theories of teaching English as CLT are applied by inner-circle of countries not by outer-circle countries. One of the studies conducted in Vietnam has evaluated the grammar-based examinations they found lack of real like or authentic language in those classrooms.

Another study of Akram and Mehmood testified the importance of implementing CLT in teacher's training progress; they asserted that CLT enriches the learner's confidence and teaching them English communicatively. GTM is only focusing on the knowledge of language not the language itself.

\section{Research Methodology}

The research is consisted of student's questionnaire, which is aimed to have student's perception about implementation of the CLT in language teaching.

\section{Sampling}

Random sampling is used in this research. 126 students' of Quest University Nawabshah of different departments are taken as the participant of the study.

\section{Research tool}

Questionnaire is used as the research tool. Multiple option questions are used in this research paper. 12 questions about the student's beliefs and attitudes of CLT are asked.

\section{Results and Discussions}

The questionnaire contains 12 questions items, which were designed to get students ideas and perception regarding English language teaching. The questions were asked to get student's attitudes and beliefs' towards CLT. The purpose of this paper is to adopt CLT in language teaching in engineering courses. 
Following are findings from the engineering student's responses using questionnaire as a research tool:

* Question No.1 What is the purpose of studying English, according to you? The first question is about the purpose of learning English language, so 50.7\% student's purpose of studying English is to get higher studies.

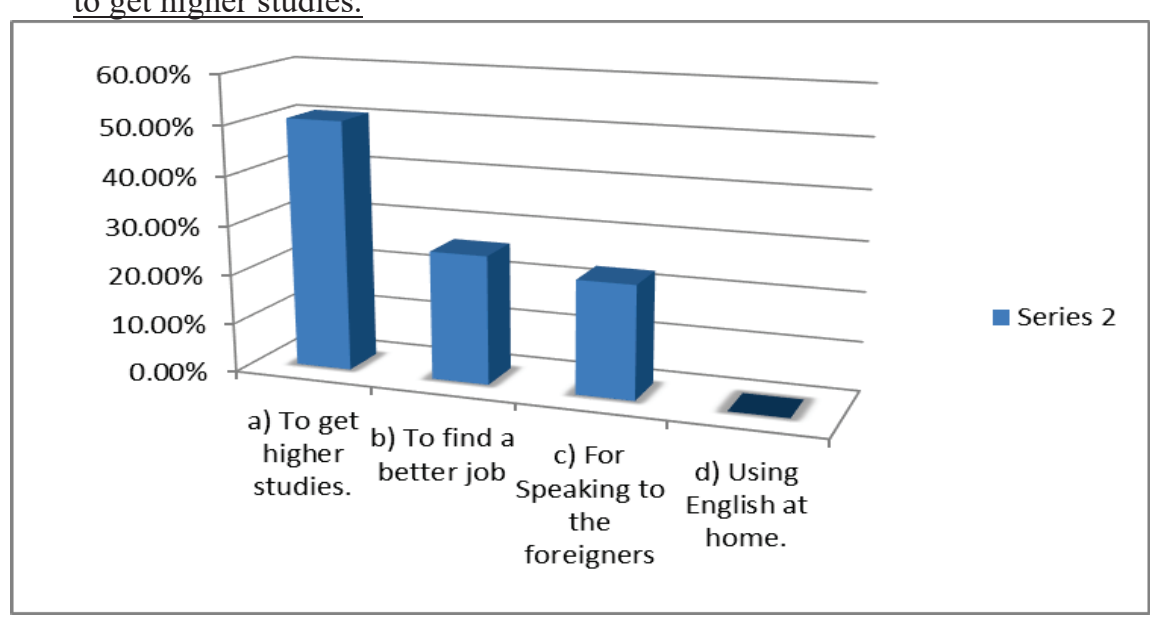

* Question No.2) You study English because you use it... the second item is knowing where students needed English language, $81.7 \%$ students wanted to learn English because they use it in their studies.

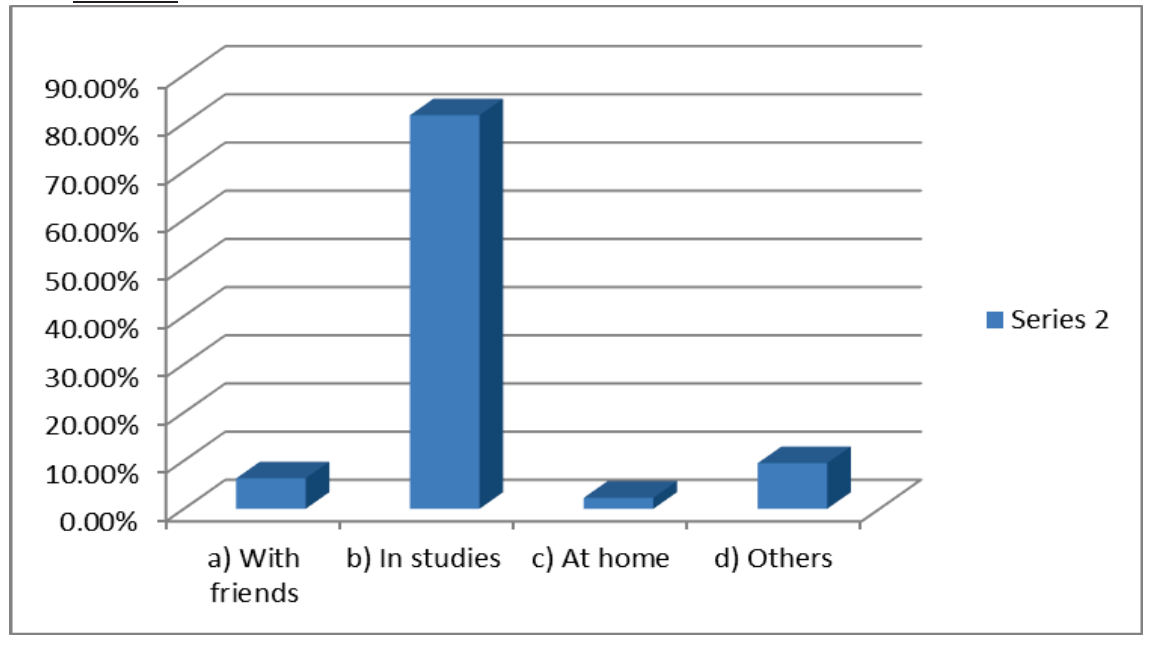

* Question No.3) I will be learning English for? The item is asked to know about the future usage of English language. $41.2 \%$ of students were those who wanted to learn English for their career.

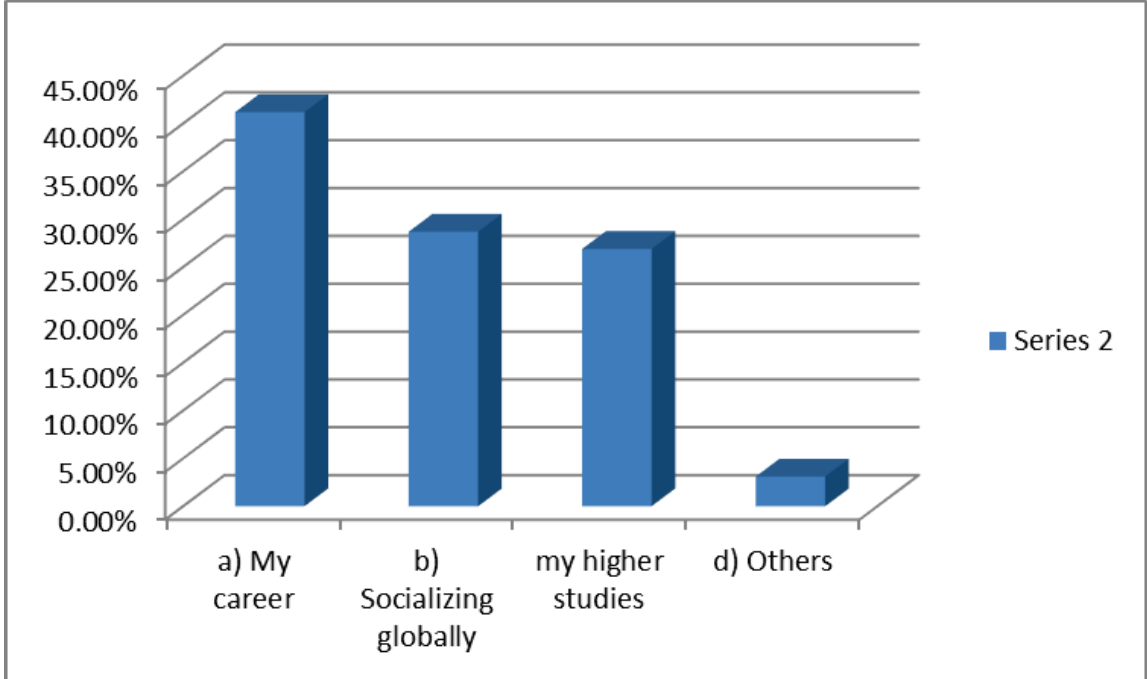


* Question N0.4) what do you think present curriculum and teaching methodologies are helping you to fulfill your needs of learning English communicatively? The question is aimed to get to know about curriculum design and the methodologies that are used in their English language classes. That curriculum and methodologies are helpful or not in learning English communicatively. According to $38.8 \%$ students, they are satisfied with the curriculum design and the teaching methodologies used in the classroom. They think their present curriculum and teaching methodologies are helping them to improve their language.

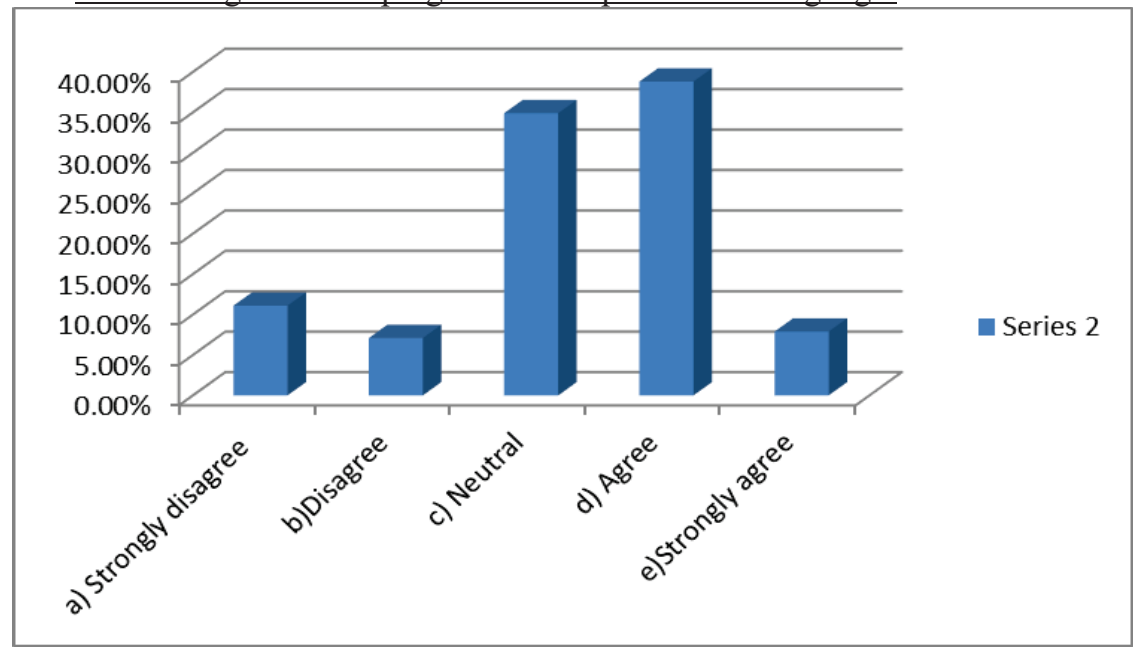

* Question No.5) If a student is not good in English than it can have........? This item is aimed to know about the value of English in their education, $72.2 \%$ students think that if students English is not good it can have bad impact on their educational performance.

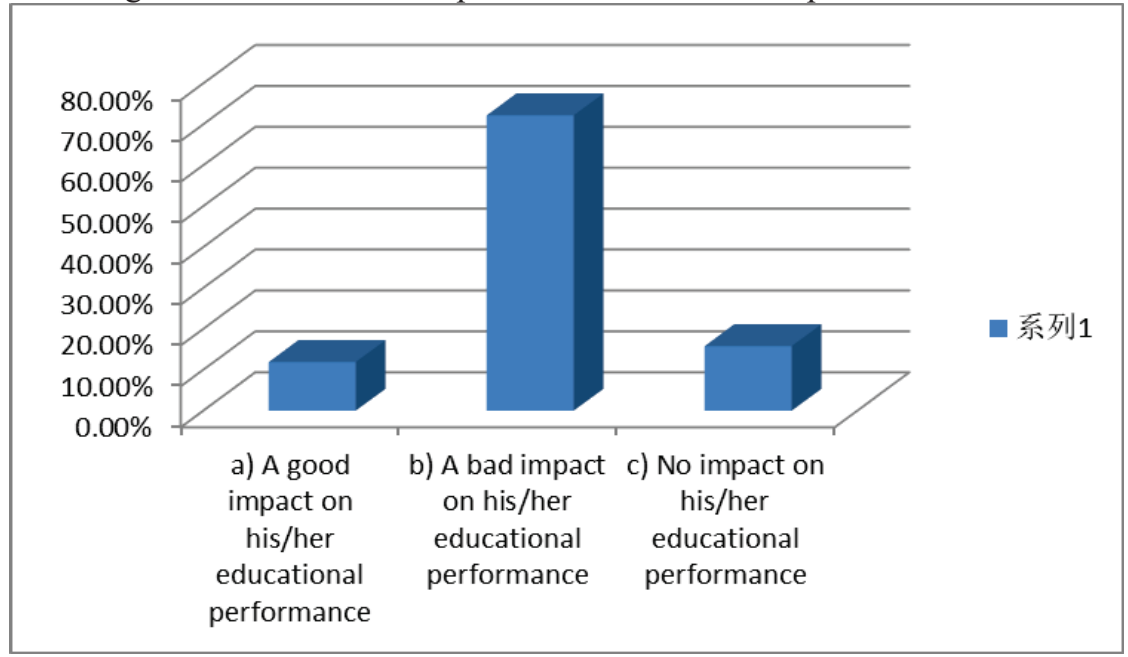


* Question No.6) Do you think if students English is not good they face difficulty while studying theoretical subjects of engineering? Item 6 is getting knowledge about the influence of English in their other subjects of engineering; majority of students agreed that if students English is not good than s/he may have difficulty in studying theoretical subjects.

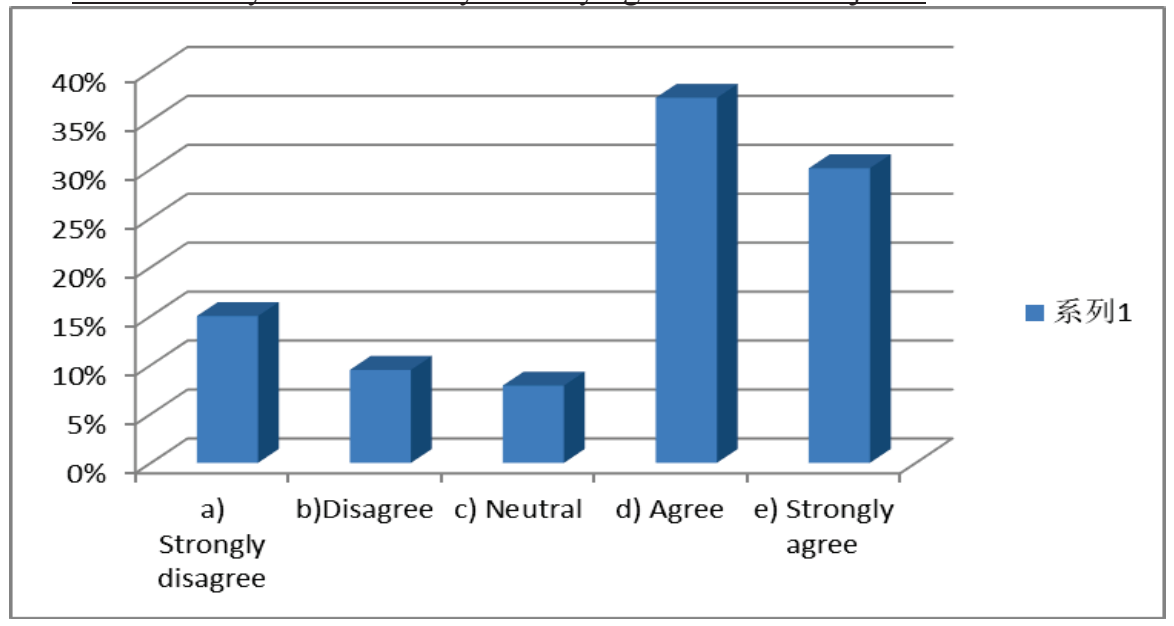

* Question No.7) what skills are focused in your language class? The question is asked to get information about the skills that are of prime importance in their language class.54.7\% students answered that Speaking skill is focused in their English Language class.

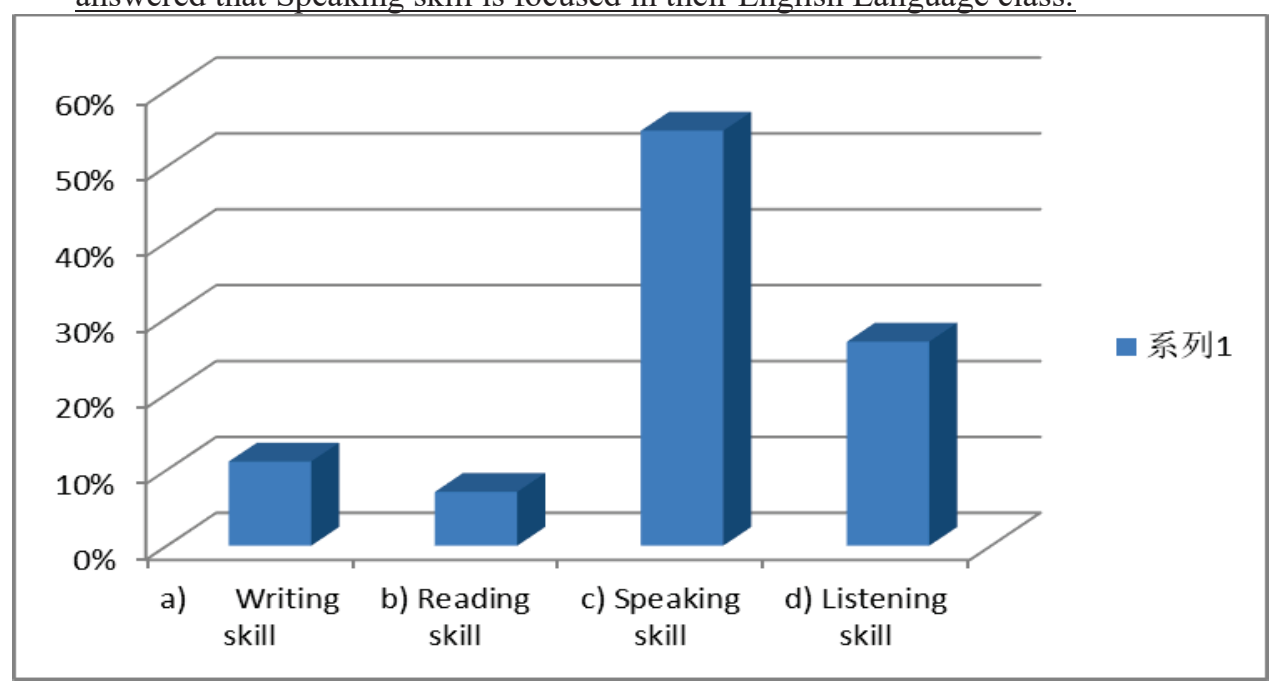

* Question No.8) which skill do you wanted to improve more? The question is asked to know about student's desired skill that they wanted to improve, $59.5 \%$ students wanted to improve their speaking skill.

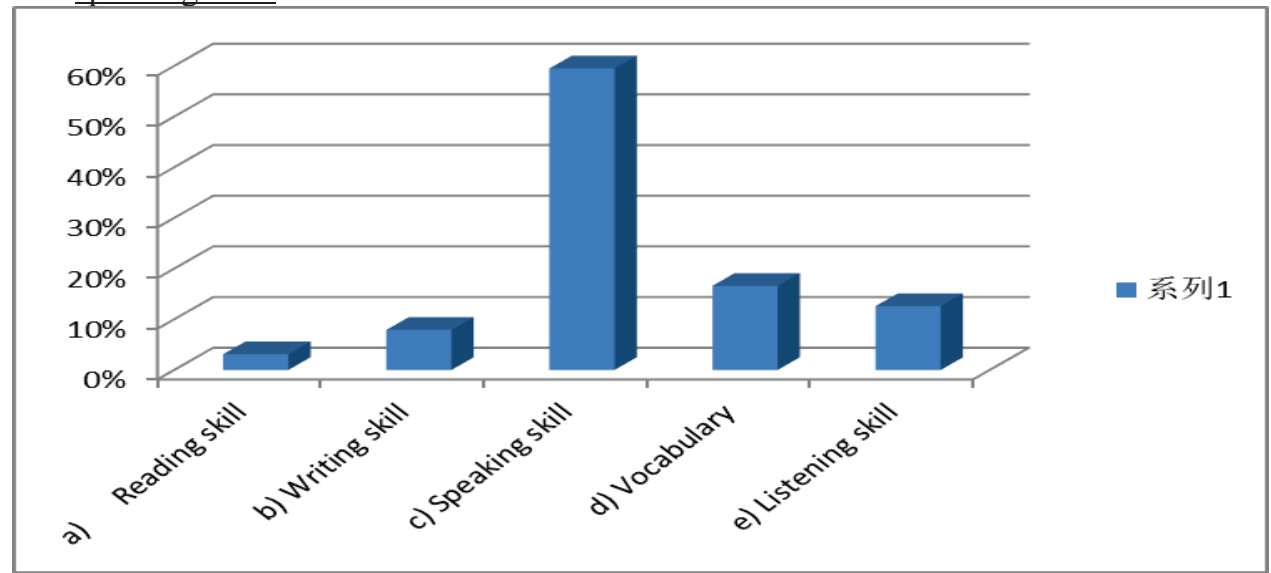


* Question No.9) your preferred learning style in classroom is... the learning style is very important in language teaching. Students were asked about their desired learning style, $64.2 \%$ of the students think there should be active role of both, teachers and students in English language classroom.

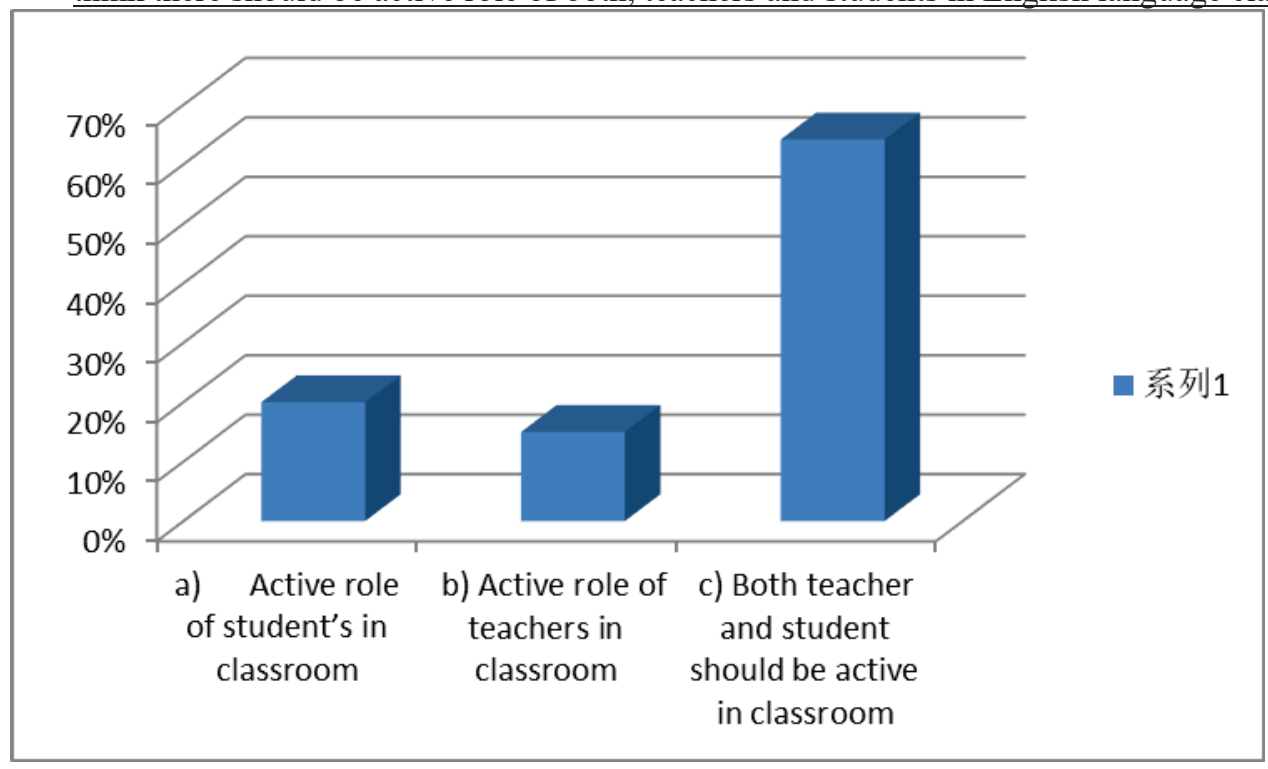

* Question No.10) How you learn well in classroom? The learning ways varies from person to person, so the students were asked about their learning ways, $67.4 \%$ students were those who think they learn well in pair or group works.

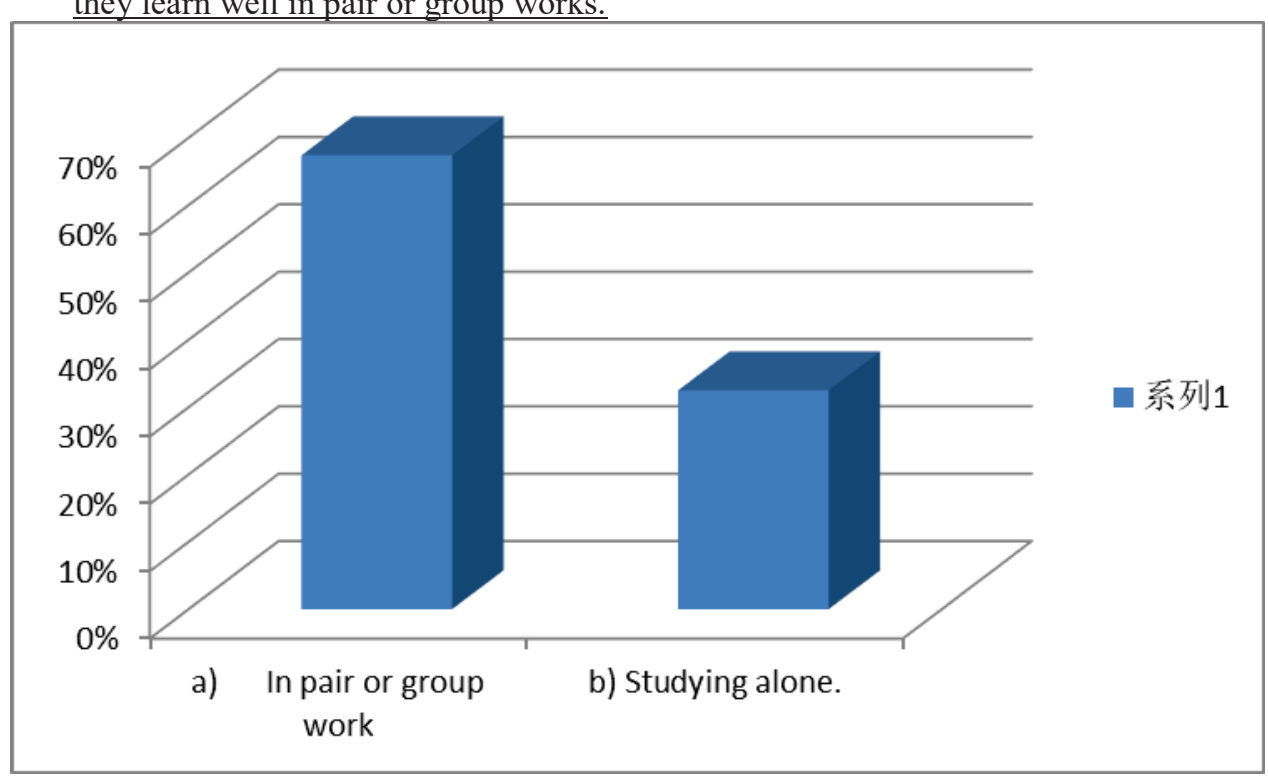


* Question No.11) what role you think teacher should play in your classroom? The role of teacher matters in the class, so when students asked about their teacher's role in the class, $59.2 \%$ students answered that their teacher's role should be as a facilitator and a guide.

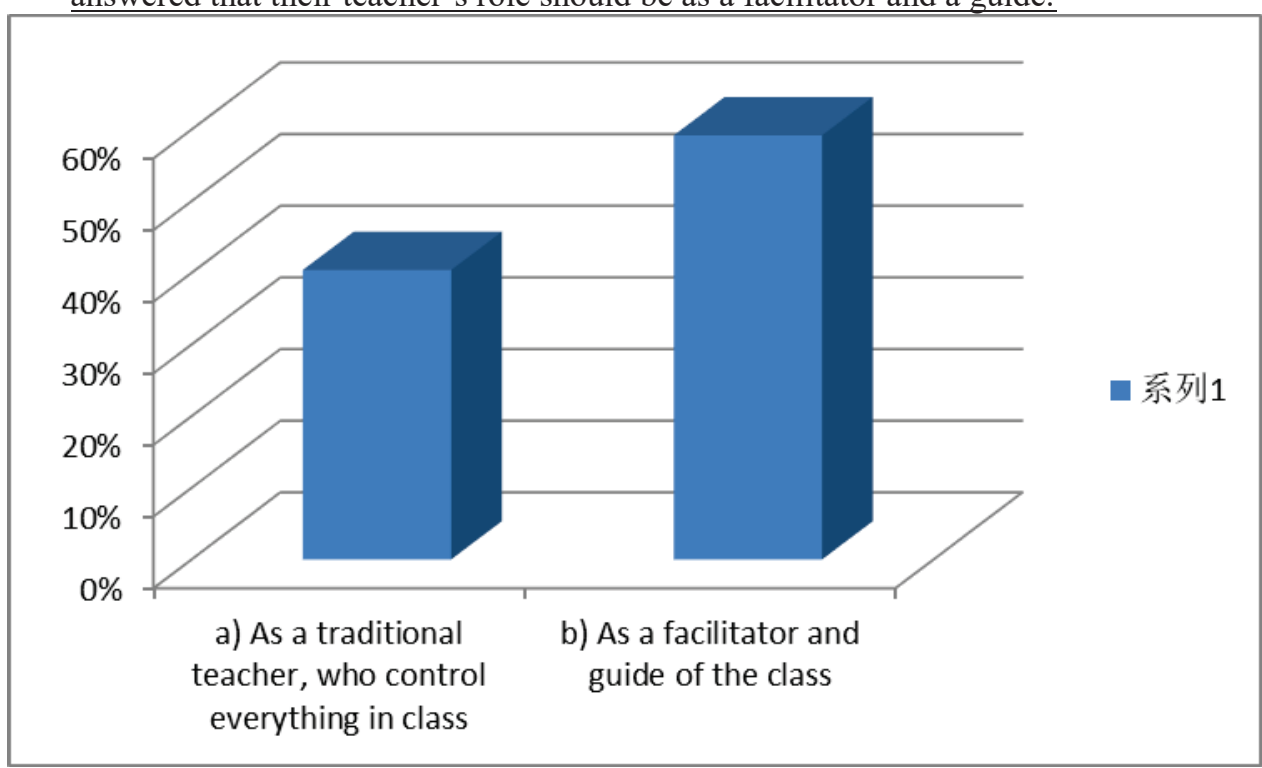

* Question No.12) what do you think your English skills are improving? Skills are very much important in English language teaching. Students were asked about their skill, either their skills are improving or not, $54.7 \%$ students think their skills are not improving.

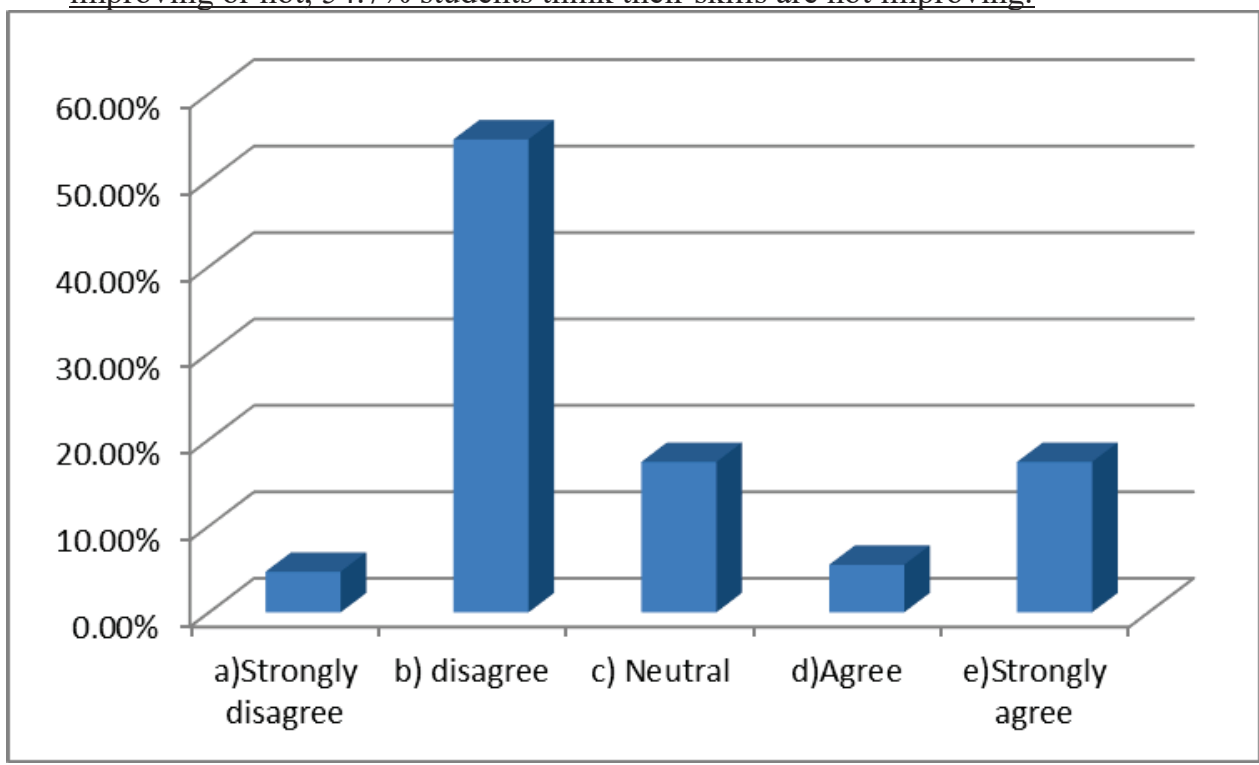

The 12 items were asked from the students about their learning style, strategies, skills and their classroom environment in terms of improving English language. Majority of students were wanted to improve their speaking skills and wanted to work in pair and in groups.

\section{Conclusion}

In this modern period, English language has become one of the most important ability in every field. The English language teaching should be focusing the engineering ESP in engineering universities. CLT should be adopted to get desired outcomes of language teaching/learning. The purpose of this study to focuses on CLT approach of language teaching. The need analysis is also carried out to improve an ESP course for engineering students of Pakistani university. The results shows that students wanted to focus on the speaking skill, and they preferred that their teacher's should be as a facilitator and as a guide not a traditional teacher. Students were also interested to work in groups and pairs rather individually. They wanted to learn English to get their higher studies. They think English is necessary for their careers. The students with bad English may have adverse effect on their academic performances. If a student is not good in English then $\mathrm{s} /$ he may be having troubles in academics and in 
professional life too. The student wanted to have an environment of the classroom which CLT approach provides. These conclusions are restricted to the particular group of students in a particular field.

\section{Reference}

$>\quad$ "Assessing Proficiency in Engineering English", IEEE transactions on professional communication, vol. 45, no. 1, (2002), pp. 40-44.

$>$ Akram, M. \& Mehmood, A. (2011). "The need of communicative approach (in ELT) in teacher training program in Pakistan", in Language in India, 11, 5: 172-178.

$>$ Chowdhry, M. R. (2010). "International TESOL training and EFL contexts", available from http://alwaysingreen.blogspot.com/2010/12/International-tesol-training-and-efl.html accessed 08July, 2011.

$>$ Ellis, G. (1996). "How culturally appropriate is the communicative approach?" in ELT Journal,50, 3: 213 218.

> Jilani, W. (2004 ). "Conditions under which English is taught in Pakistan : an applied linguistic perspective", in SARID Journal, 1, 1: 01-09. Li, D. (1998).

$>$ "It's always more difficult than you plan and imagine: teachers' perceived difficulties in introducing the communicative approach in South Korea", in TESOL Quarterly, 3, 4: 677-703.

$>$ M. H. Long, "Methodological issues in learner needs analysis", Long M. H. (ed.) Second Language Needs Analysis, Cambridge: Cambridge University Press, (2005), pp. 19-76.

$>$ Wenjie, C. (2009). "Using CLT to improve speaking ability of Chinese non-English major students", M.A.thesis, University of Wisconsin Platteville. Retrieved from http//minds.wisconsin.edu/ bitstream/handle accessed on 18 September, 2011.

\section{Appendix}

Please read the questions carefully and from these options put a cross in front of your responses.

1. What is the purpose of studying English, according to you?
a) To get higher studies.
b) To find a better job
c) For Speaking to the foreigners
d) Using English at home.

2. You study English because you use it:
a) With friends
b) In studies
c) At home
d) Others

3. I will be learning English for?
a) My career
b) Socializing globally
c) my higher studies
d) Other

4. What do you think present curriculum and teaching methodologies are helping you to fulfill your needs of learning English communicatively?
a) Strongly disagree
b) Disagree
c) Neutral
d) Agree
e) Strongly agree

5. If a student is not good in English than it can have........?
a) A good impact on his/her educational performance
b) A bad impact on his/her educational performance
c) No impact on his/her educational performance

6. Do you think if students English is not good they face difficulty while studying theoretical subjects of engineering?
a) Strongly disagree
b) Disagree
c) Neutral
d) Agree
e) Strongly agree

7. What skills are focused in your language class?

a) Writing skill 
b) Reading skill

c) Speaking skill

d) Listening skill

8. Which skill do you wanted to improve more?
a) Reading skill
b) Writing skill
c) Speaking skill
d) Vocabulary
e) Listening skill

9. Your preferred learning style in classroom is...

a) Active role of student's in classroom

b) Active role of teachers in classroom

c) Both teacher and student should be active in classroom $\backslash$

10. How you learn well in classroom?
a) In pair or group work

b) Studying alone.

11. What role you think teacher should plays in your classroom?

a) As a traditional teacher, who control everything in class

b) As a facilitator and guide of the class

12. What do you think your English skills are improving?
a) Strongly disagree
b) Disagree
c) Neutral
d) Agree
e) Strongly agree 